\title{
Allergenicity Assessment of a Genetically Modified Protein-Recombinant Human Lactoferrin
}

\author{
${ }^{1}$ College of Food Science and Nutritional Engineering, China Agricultural University, China \\ ${ }^{2}$ Department of Dermatology, the First Affliated Hospital of Herbin Medical University, China \\ ${ }^{3}$ Department of Food Science \& Technology, University of Nebraska, USA \\ ${ }^{4}$ State Key Laboratory for Agro Biotechnology, China Agricultural University, China \\ ${ }^{5}$ The Supervision, Inspection and Testing Center of Genetically Modified Organisms, Ministry of Agriculture, China
}

Cui Zhou ${ }^{1}$, Na Sun ${ }^{1}$, Jing Wang ${ }^{1}$, Jing Lu ${ }^{1}$, Jing Tian², Richard E Goodman ${ }^{3}$, Ning Li $^{4}$, Huilian Che ${ }^{1,5 *}$ and Kunlun Huang ${ }^{1,5 *}$

\begin{abstract}
Background: Recombinant human lactoferrin (rhLF) has previously suggested serving as food additive due to the natural iron binding properties that provide anti-microbial activity. Recombinant cows have been produced that express $h L f$ in milk. However, the potential allergenicity of $h L f$ has not been previously assessed. This research is conducted to evaluate the potential allergenicity of rhLF as a prerequisite for food use.
\end{abstract}

Methods: A comparison was made of the bioactivity, physicochemical properties and glycosylation profile between rhLF and natural hLF. The amino acid sequence of hLf was compared to known allergens. Additionally, the stability of hLf in pepsin and a human serum IgE test was conducted.

Results: The amino acid identity between rhLF and the minor allergen bovine lactoferrin was $71.4 \%$. However, every human is exposed to $\mathrm{hLf}$ constantly without demonstrated allergies. The $\mathrm{hLF}$ was digested rapidly by pepsin and was not specifically bound by lgE using serum from patients who are allergic to egg and milk.

Conclusion: Based on these results, the potential allergenicity of rhLF as produced in bovine milk is quite low. It may be added into formula powder or food to improve nutrition composition.

Keywords: Recombinant human lactoferrin; Amino acid identity; pepsin stability; serum screen; Allergenicity

\section{Introduction}

Human lactoferrin (hLF) is known to be a multifunctional protein of the transferrin family. It is a glycoprotein of approximately $80 \mathrm{KDa}$ and is present in various human secretory fluids including milk, saliva, tears and nasal secretions as well as being abundant in neutrophils [14]. The hLf protein includes 703 amino acids as a single polypeptide chain that folds into two similar globular lobes-C- and N-terminal regions. The structure is maintained by multiple intra-chain disulfide bonds and the lobes are connected by a short $\alpha$-helical region. The isoelectric point of hLf is 8.7 and there are two iron binding sites and 5 potential asparagine-linked glycosylation sites in the molecule [5]. The degree of glycosylation of the protein varies with the tissue of expression and the metabolic status of the producing cells [6]. Each lactoferrin molecule can reversibly bind two ions of iron with high affinity, but it may also bind zinc, copper or other metals with lower affinity [7]. After combining with iron, it forms a reddish complex. The affinity for iron is 300 times higher than that of transferrin, although the amino acid sequences are $60 \%$ identical [8]. The characteristics of hLF were first published in 1984 and the similarities to transferrin were noted [5]. The concentration of lactoferrin in human milk is approximately $7 \mathrm{~g} / \mathrm{L}$, much higher than in milk of non-primate species of mammals.

Human lactoferrin has been demonstrated to have antibacterial, antiviral, anti-inflammatory and antioxidant properties [9-16]. It can interact with human cells to modulate the inflammatory process and innate defense reactions [17]. Lastly, dietary hLF provides an important mechanism for efficient iron absorption, especially in the neonate, as well as promoting intestinal epithelial cell growth [17].

Researchers have considered using hLF in a wide variety of applications due to its bioactivities. Potential applications include the prophylactic treatment of inflammatory disease $[18,19]$ and iron deficiency [20]. It has also been proposed for use as a food additive [21] to reduce microbial spoilage.

Large-scale production of hLF is necessary to meet the potential demand for its many uses. Although several efficient methods have been used to purify hLF from breast milk [22-26], its supply is quite limited, expensive and there is concern regarding the potential for naturally purified hLF to transmit disease vectors such as hepatitis, human immunodeficiency virus and many other difficult to detect viral diseases. These obstacles limit application of this useful protein. Recent developments in biotechnology have allowed production of recombinant hLF (rhLF) using transformed mammalian cells in culture and by transformed bacteria in fermentation [27-29]. However the yields have been low and since hLF is a highly folded, cross-linked and glycosylated protein, there has not been good success. A recent publication demonstrated successful production of rhLF in transgenic mice with production targeted to the mammary gland [30,31]. A previous attempt to produce rhLF in rice has so far not been fully successful as the plant glycosylation system modifies added asparagine linked glycans differently than mammalian cells and regulators of GMO's (Genetically Modified Organism's) have not approved the GM

${ }^{*}$ Corresponding authors: Huilian Che, College of Food Science and Nutritional Engineering, China Agricultural University, Beijing 100083, China, Tel: 8610+62738552; Fax: 86-10+62323465; E-mail: chehuilian@cau.edu.cn

Kunlun Huang, College of Food Science and Nutritional Engineering, China Agricultural University, Beijing 100083, China, Tel: 86-10+62738552; Fax: 8610+62323465; E-mail: hkl009@163.com

Received February 01, 2013; Accepted February 28, 2013; Published March 05, 2013

Citation: Zhou C, Sun N, Wang J, Lu J, Tian J, et al. (2013) Allergenicity Assessment of a Genetically Modified Protein-Recombinant Human Lactoferrin. J Aller Ther S3: 002. doi:10.4172/2155-6121.S3-002

Copyright: (C) 2011 Zhou C, et al. This is an open-access article distributed unde the terms of the Creative Commons Attribution License, which permits unrestricted use, distribution, and reproduction in any medium, provided the original author and source are credited. 
(Genetically Modified) rice as acceptable. Together the data suggested that utilization of transgenic expression of rhLF in bovine mammary glands might provide an efficient mechanism for industrial scale production of hLF.

Investigators at China Agricultural University produced two transgenic cows, one that secreted rhLF at $2.5 \mathrm{~g} / \mathrm{L}$ and a second that secreted rhLF at $3.4 \mathrm{~g} / \mathrm{L}$ in their milk. Transformation was accomplished through microinjection of a bacterial artificial chromosome (BAC) containing a copy of genomic clone $(\sim 150 \mathrm{~kb})$ of hLF into bovine fibroblasts, followed by somatic cell cloning and transfer to the uterus of recipient cows with a small number of transgenic calves being produced [32]. In previous studies of the rhLF transgenic cows the composition of milk and milk powder from transgenic cows were compared to that from non-transgenic cows. The results did not demonstrate any significant differences with the exception of the presence of high levels of rhLF in the transgenic milk [32,33]. Biochemical characterization of rhLF and hLF demonstrated slight differences in molecular weight, with rhLF being slighly lower than hLF. The difference may be due to small variations in glycosylation profiles between the two proteins. Detailed characterization of glycosylation patterns of rhLF expressed in bovine mammary glands demonstrated diverse structures [34]. The results indicated that hLF and rhLF were glycosylated at the same two sites: Asn138 and Asn479. The differences between rhLF and hLF in $\mathrm{N}$-glycosylation profiles were consistent with the widely held view that glycosylation is species- and tissue/cell- specific [34]. Importantly, neither glycan structures (fucose and xylose substitutions at specific sites) that are known to be responsible for irrelevant IgE binding in some subjects [35] nor alpha-galactose that has been demonstrated to cause adverse immunological reactions [36] was detected on rhLF [37].

The susceptibility to proteolysis of rhLF was studied and compared with that of natural hLF [32]. Results of the in vitro tests indicated that pepsin can digest rhLF completely in $60 \mathrm{~min}$, which was similar to that of natural hLF.

Finally, the in vitro antibacterial effect of rhLF, iron binding and releasing properties was researched and the comparison was conducted between rhLF and hLF. The results also demonstrated that rhLF's properties are similar to hLF [32].

As a transgenic protein, it is necessary to evaluate the allergeinicity of rhLF expressed in GM cows according to international standard. In this study a bioinformatics analysis, tests of the stability of rhLF in pepsin and the serum reactivity tests were conducted to evaluate rhLF's potential allergenicity. An important under-stated consideration in the Codex guidelines and various country regulations is the history of safe use $[38,39]$. Since hLF is produced in secretory glands of the human body including mammary, lacrimal and salivary glands as well as in polymorphonuclear leukocytes, human exposure to the protein is not only common, but constant. There are no reports of allergy to this selfprotein. Thus the likelihood of allergy to an exogenous source of the protein, if it has the same amino acid sequence is negligible.

\section{Materials and Methods}

\section{Bioinformatics analysis}

On the basis of the recognized international guidelines for evaluating GMO's the allergenicity of rhLF expressed in the milk of transgenic cow was evaluated simply based on bioinformatics and resistance to digestion by pepsin. The amino acid sequence comparison for rhLF was conducted with three databases; FARRP (http://www.allergenonline. com), SDAP (http://fermi.utmb.edu/SDAP/sdap_src.html) and ADFS
(http://allergen.nihs.go.jp/ADFS/), which are widely used in the world at present [40-42]. The primary methods of evaluation were searches for " 80 amino acid alignments with greater than $35 \%$ identity by FASTA" and " 8 amino acid exact matches". Because of the peptide match of 6 continuous amino acids to known allergens will result in many false positives [41,42] and produce many random, irrelevant matches [43], this method was not used in this evaluation.

\section{Stability to pepsin digestion}

The digestion resistance of rhLF was tested according to published methods [44]. Stimulated gastric fluid (SGF) was prepared to include pepsin purchased from Sigma Chemical (Shanghai, Sigma-Aldrich China, Inc), with a stated activity of $4220 \mathrm{U} / \mathrm{mg}$ of protein as analyzed

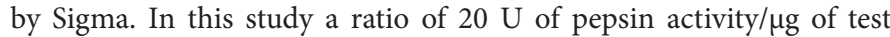
protein, about 5:1 (w/w), was used throughout the study. The other materials, bovine serum albumin (BSA) and bovine $\beta$-lactoglobulin (BLG) were also obtained from Shanghai, Sigma-Aldrich China, Inc. for use as control proteins. It has been reported that the BSA is labile and the BLG is stable to SGF in standard condition [44]. Samples of digestion products were evaluated in SDS-PAGE with gel staining according to standard conditions. Images of stained gels were captured and compared using a gel imaging instrument (GelDoc-It Imaging System, P/N 95-0441-02, USA).

\section{Human serum test}

The results of amino acid sequence comparison showed that rhLF shares $71.4 \%$ identity with bLF and $52.2 \%$ identity with ovotransferrin, two reported allergens [45-48]. As the serum screen is recommended in some guidelines, human serum tests with rhLF were conducted to further evaluate the potential allergenicity of rhLF using sera from donors allergic to milk or egg.

Sera of consenting donors were collected under institutional review board approval from 12 egg-allergic subjects and 21 milk-allergic individuals for use in this study. The donors were diagnosed as allergic to egg or milk based on clinical histories, skin prick test (SPT) and specific IgE tests (allergic specific Pharmacia UniCAP tests). The level of egg- or milk- specific IgE in all of the sera samples were $>3.5 \mathrm{KUA} / \mathrm{L}$. Additionally, serum samples from individuals were mixed as serum pool to be used as negtive control.

Immunoblots were conducted according to the previous protocol [49-51] with some modifications. In brief, the SDS-PAGE was conducted using $400 \mathrm{ng}$ purified rhLF, bLF, hLF (kindly provided by professor Li Ning, Purity: 98\%) and $10 \mu \mathrm{g}$ protein extract prepared from a standard egg powder (Lot. $1452807 \mathrm{v}$, USA) or from milk powder (NO. 1549, USA.) with samples loaded in adjacent wells of the gel. Following separation of proteins by electrophoresis, proteins were either stained with Coomassie blue or transferred to nitrocellulose membranes (NC) for immunoblot. Membranes were then rinsed with distilled water and blocked by submersion in 3\% BSA in PBS buffer for $2 \mathrm{~h}$ at room temperature. After washing, the blocked membranes were incubated $2 \mathrm{~h}$ at room temperature in individual allergic sera or control sera, which had been diluted 1:20 (v/v) in blocking buffer $30 \mathrm{~min}$ prior to adding to the membrane. The membranes were washed 6 times in TBST $(0.02 \mathrm{M}, 0.05 \%$ Tween-20), then incubated for $1 \mathrm{~h}$ in monoclonal mouse anti- human IgE conjugated with horseradish peroxidase (HRP) (kindly provided by professor Li Ning) that was dilluted 1:8000 (v/v) in blocking solution. After 6 washes in TBST solution, detection was achieved using ECL (enhanced chemiluminescence; Amersham 
BioSciences, Piscataway, NJ; No. RPN2106), with exposure for 3 min on the X-ray films.

\section{Results}

\section{Bioinformatics comparison}

Results of the overall FASTA alignment demonstrated that rhLF shares $71.4 \%$ identity to bovine lactoferrin (bLF), $52.2 \%$ to ovotransferrin and $51.9 \%$ to ovotransferrin precursor, using the FARRP allergen database (Figure 1). Additionally the results of " 80 amino acid alignments" showed the sequence of rhLF contains 532 sliding 80 amino acid alignments hit $>35 \%$ to bLF or ovotransferrin or ovotransferrin precursor using the sliding window search on the FARRP website (Figure 1)

\section{Pepsin stability of rhLF}

The results if digestion experiments are shown in figure 2. The samples of BSA were digested completely in SGF in $15 \mathrm{~s}$ and BLG samples were still clearly visible after 60 min digestion by pepsin. The rhLF was digested in $15 \mathrm{~s}$ by pepsin as found in a previous study [32].

\section{Human serum tests}

The results of Bioinformatics comparison suggested rhLF might act as a cross-reactive allergen for some consumers allergic to bovine milk or hen's eggs and based on guideline recommendations, human serum testing should be performed. However, since hLF is widely expressed in every human, and there are no data to support subjects allergic to human lactoferrin, there is no risk and there should not be a need to perform serum tests. In order to satisfy regulatory requirements and in anticipation of questions from consumers or regulators, a decision was made to test serum IgE binding.

As shown in figure 3, after SDS-PAGE and stained with coomassie brilliant blue, there are mainly 4 protein bands, which are about 65 KD (Bovine Serum Albumin, BSA), 34 KD, 26 KD (Caseins, CAS) and $18 \mathrm{KD}$ ( $\beta$-lactoglobulin, $\mathrm{LG}$ ) in the extraction of standard milk powder. 10 protein bands were evident in the egg powder and their molecular weight were approximately $230 \mathrm{KD}, 150 \mathrm{KD}, 130 \mathrm{KD}, 83 \mathrm{KD}$ (Ovotransferrin, OVT), $72 \mathrm{KD}, 60 \mathrm{KD}, 45 \mathrm{KD}$ (Ovalbumin, OVA), 40 $\mathrm{KD}, 34 \mathrm{KD}, 28 \mathrm{KD}$ (Ovomucoid, OVM). Since the standard egg powder used in this study was whole egg powder, it is assumed that the high weight molecules are from the yolk. The three obvious banding in lane 3, 4 and 5 were rhLF, hLF and bLF respectively, and their MW were all about $80 \mathrm{KD}$.

The immunoblot results are shown in figure 4, there was no visible binding band in the membrane that incubated with control serum from healthy donors (Figure 4B). The notable IgE binding reaction was detected in the protein bands of $150 \mathrm{KD}, 83 \mathrm{KD}, 45 \mathrm{KD}, 34 \mathrm{KD}$ in egg powder and of $65 \mathrm{KD}, 26 \mathrm{KD}, 18 \mathrm{KD}$ in milk powder. These proteins maybe the important allergens, which named as ovotransferrin (OVT), ovabumin (OVA), ovomucoid (OVM), bovine serum albumin (BSA), casein (CAS) and lactoglobulin (LG) in egg and milk (Figures $4 \mathrm{C}$ and 4D). This is in accordance to previous study [52]. And finally, there was no visible IgE binding reaction to purified rhLF, hLF and bLF in all of the test serum samples (Figures 4C and 4D). Because of the sensitivity of this immunoblot and detection method which used ECL, IgE should be detectable at the level of pg and the banding reaction of protein and its antibody was detected in our preliminary experiment when the loaded dose was $40 \mathrm{ng}$ (Figure 4A). So the lack of apparent IgE binding to hLF and rhLF demonstrates that there would not be any IgE binding to the rhLF expressed in cow's milk.

\section{Discussion}

As one of functional proteins that is secreted by multiple tissues of the human body, hLF is always present in various organs and fluids (blood, lymph, milk, saliva, semen, and tears) of humans. Dietary exposure is common for infants who are breast fed as well as continuing exposure through saliva and bile. Exposure to lactoferrin certainly starts before birth. However, no evidence of allergy to human lactoferrin has been reported. It's common and high expression level in various fluids and in PMNs is expected to lead to immune tolerance rather than allergy or other adverse immune responses to self [53]. Immune tolerance is primarily formed in the embryonic period and soon after birth when the immature T lymphocyte and B lymphocyte contact the self-protein or the other substance and this can be maintained throughout life.

In previous studies it was demonstrated that the rhLF expressed in the milk produced from transgenic cows has similar in antimicrobial, iron binding and growth promoting activity of epithelial cells [32]. An earlier study of the glycosylation patterns of rhLF were compared to natural hLF [34]. The Cross-reactive Carbohydrate Determinant (CCD) type glycans (xylose or fucose substituted complex N-linked glycans) and alpha-gal are often considered as potential allergenic carbohydrates in protein [54-56]. The results show that only a small amount of Neu5Gc was detected by HPLC and no other antigenic carbohydrates were found [34]. And the glycosylation profile of rhLF was similar to hLF.

In recent years, a number of international organizations, including the Food and Agricultural Organization (FAO) and World Health Organization (WHO) and Codex Alimentarius Commission (CAC) developed recommendations for the evaluation of GMO's for potential allergenicity in foods. The International Food Biotechnology Council

\begin{tabular}{|c|c|c|c|c|c|c|c|c|c|}
\hline \multirow{2}{*}{$\begin{array}{c}\text { Hit } \\
\#\end{array}$} & \multirow{2}{*}{ Defline } & \multirow{2}{*}{ Species } & \multirow{2}{*}{$\begin{array}{l}\text { Best } \\
\% \text { ID }\end{array}$} & \multirow{2}{*}{$\begin{array}{l}\text { \# Hits } \\
>\mathbf{3 5} \%\end{array}$} & \multicolumn{3}{|c|}{ Full Alignment } & \multicolumn{2}{|c|}{ Links } \\
\hline & & & & & E-val & $\%$ ID & length & NCBI & Details \\
\hline 1 & gi | 30794292 | ref |NP_851341.1 | lactotransferrin prec & Bos taurus & $83.80 \%$ & 532of532 & $4.9 \mathrm{e}-204$ & $71.40 \%$ & 611 & gi $\mid 30794292$ & $\mathrm{GO} !$ \\
\hline 2 & gi $|757851|$ emb |CAA26040.1 | ovotransferrin [Gallus g & Gallus gallus & $66.70 \%$ & 532of532 & $2.3 \mathrm{e}-137$ & $52.60 \%$ & 618 & gi $\mid 757851$ & GO! \\
\hline 3 & gi | 1351295 | sp |PO2789.2 | TREF_CHICK RecName: Full=Ov & Gallus gallus & $66.70 \%$ & 532of532 & $3.1 \mathrm{e}-138$ & $52.90 \%$ & 618 & gi | 1351295 & GO! \\
\hline
\end{tabular}

The amino acid sequence of rhLF is GRRRSVQWCAVSQPEATKCFQWQRNMRKVRGPPVSCIKRDSPIQCIQAIAENRADAVTLDGGFIYEAGLAPYKLRPVAAEVYGTERQPRTHYYAVAVVKKGGSFQLNELQGLKSCHTGLRRTAGWNVPIGTLRPFLNWTGPPEPIEAAVARFFSASCVPGADKGQFPNLCRLCAGTGENKCAFSSQEPYFSYSGAFKCLRDGAGDVAFIRESTVFEDLSDEAERDEYELLCPDNTRKPVDKFKDCHLARVPSHAVVARSVNGKEDAIWNLLRQAQEKFGKDKSPKFQLFGSPSGQKDLLFKDSAIGFSRVPPRIDSGLYLGSGYFTAIQNLRKSEEEVAARRARVVWCAVGEQELRKCNQWSGLSEGSVTCSSASTTEDCIALVLKGEADAMSLDGGYVYTAGKCGLVPVLAENYKSQQSSDPDPNCVDRPVEGYLAVAVVRRSDTSLTWNSVKGKKSCHTAVDRTAGWNIPMGLLFNQTGSCKFDEYFSQSCAPGSDPRSNLCALCIGDEQGENKCVPNSNERYYGYTGAFRCLAENAGDVAFVKDVTVLQNTDGNNNEAWAKDLKLADFALLCLDGKRKPVTEARSCHLAMAPNHAVVSRMDKVERLKQVLLHQQA KFGRNGSDCPDKFCLFQSETKNLLFNDNTECLARLHGKTTYEKYLGPQYVAGITNLKKCSTSPLLEACEFLRK

Figure 1: Results of bioinformatics analysis of hLF. It was compared to allergens contained in the FARRP allergen database, version 11 
Citation: Zhou C, Sun N, Wang J, Lu J, Tian J, et al. (2013) Allergenicity Assessment of a Genetically Modified Protein-Recombinant Human Lactoferrin. J Aller Ther S3: 002. doi:10.4172/2155-6121.S3-002
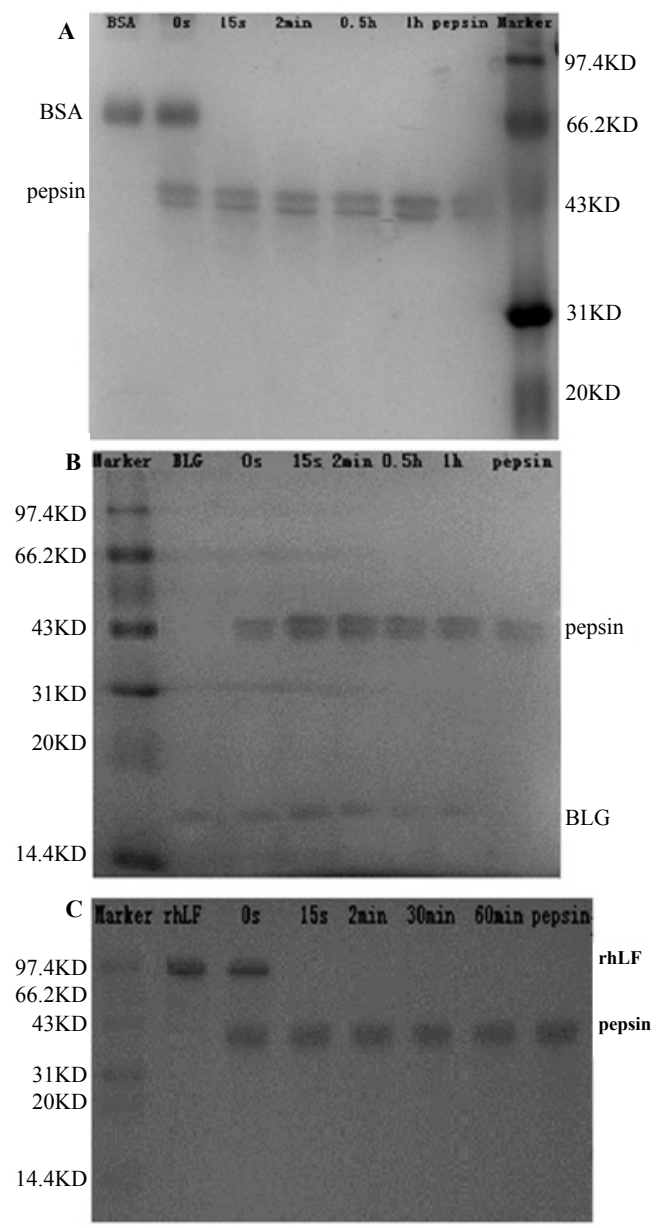

Figure 2: Result of three proteins digested in a standard in vitro pepsin digestion assay. The stained gel images show that BSA was rapidly digested, while BLG was relatively resistant to SGF. The rhLF test protein was digested in less than $15 \mathrm{~s}$

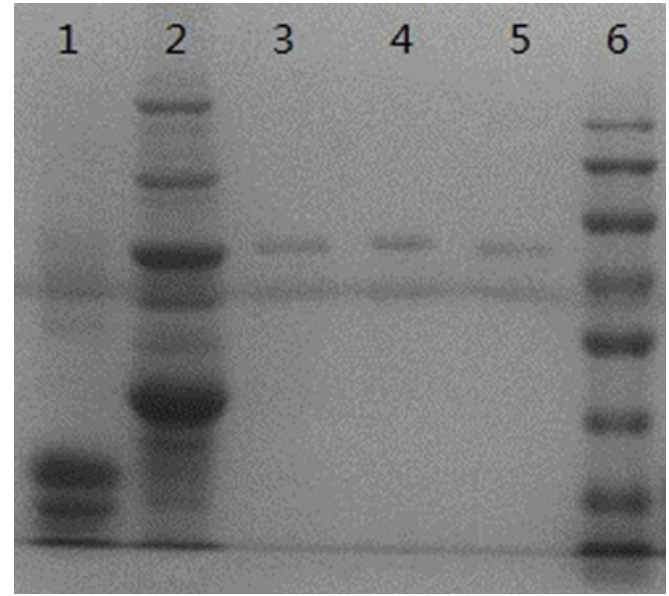

Figure 3: SDS-PAGE of standard egg powder and milk powder extracts. Lane 1: standard milk powder extracts $(10 \mu \mathrm{g})$; Lane 2: standard egg powder extract $(10 \mu \mathrm{g})$; Lane 3: recombinant human lactoferrin (rhLF, $400 \mathrm{ng})$; Lane 4: human lactoferrin (hLF, $400 \mathrm{ng}$ ); Lane 5: bovine lactoferrin (bLF, $400 \mathrm{ng}$ ); Lane 6: molecular weight marker (the standard weight band is $170 \mathrm{KD}, 130 \mathrm{KD}, 95 \mathrm{KD}$ $72 \mathrm{KD}, 55 \mathrm{KD}, 43 \mathrm{KD}, 34 \mathrm{KD}, 26 \mathrm{KD}$ and $10 \mathrm{KD}$ respectively). The rhLF, hLF and bLF were detected in the gel at a loaded dose of $400 \mathrm{ng}$.
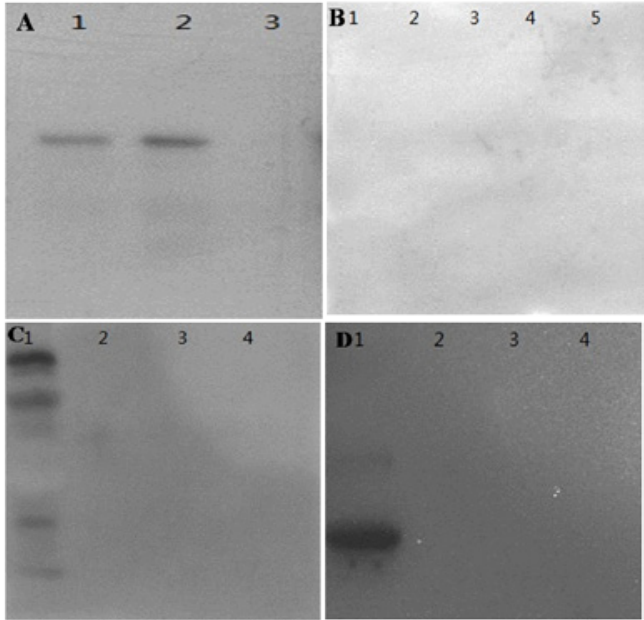

Figure 4: Results of representative IgE Immunoblots from samples of standard egg and milk. Picture A was the positive control of rhLF and hLF using specific antibody to rhLF and hLF. The order of the laoded samples in picture A were Lane 1: recombinant human lactoferrin (rhLF, $40 \mathrm{ng}$ ), Lane 2: human lactoferrin (hLF, $40 \mathrm{ng})$, Lane 3: $\mathrm{ddH}_{2} \mathrm{O}(15 \mu \mathrm{l})$. The order of the laoded samples in the picture $B$ was as Lane 1: standard milk powder extracts $(10 \mu \mathrm{g})$, Lane 2: standard egg powder extracts $(10 \mu \mathrm{g})$, Lane 3: recombinant human lactoferrin (rhLF, $40 \mathrm{ng}$ ), Lane 4: human lactoferrin (hLF, $40 \mathrm{ng}$ ), Lane 5: bovine lactoferrin (bLF, $40 \mathrm{ng}$ ). The serum used in picture $B$ to incubate the membrane was mixture of 5 control sera. In picture $C$ and $D$, Lane 1: standard egg powder extracts in $\mathrm{C}(10 \mu \mathrm{g})$ or standard milk powder extracts in $\mathrm{D}(10 \mu \mathrm{g})$, Lane 2: recombinant human lactoferrin (rhLF, $40 \mathrm{ng}$ ), Lane 3: human lactoferrin (hLF, $40 \mathrm{ng}$ ), Lane 4: bovine lactoferrin (bLF, $40 \mathrm{ng}$ ). The $\mathrm{C}$ was obtained by incubating the memnrane with a pool contained 12 sera from individual donors allergic to egg. The level of egg specific $\mathrm{IgE}$ in all of the 12 sera samples were $>3.5 \mathrm{KUA} / \mathrm{L}$. Finally, 21 sera donated from individual donors allergic to milk were mixed to incubate the membrane $D$, and the level of milk specific lgE in the serum was also $>3.5 \mathrm{KUA} / \mathrm{L}$. In egg and milk there were sevral proteins binded to specific allergic serum, while the rhLF, hLF and bLF. This indecate that there was not cross reaction between rhLF and egg, milk.

and the Allergy and Immunology Institute of the International Life Sciences Institute (IFBC/ILSI) presented a decision-tree approach to evaluate the potential allergenicity of the exogenous proteins in genetically modified crops intended for food use [37] in 1996. If the source of the gene (donor) is known to cause allergies, serum from a number of individuals allergic to the donor would be used to test for IgE binding to the protein encoded by the transferred gene. The amino acid sequence would also be compared to those of known allergenic proteins and if any eight amino acid segment was identical to a segment of an allergen, serum from a number of subjects allergic to the source of the allergenic protein would be used in similar tests. The stability of the protein would also be tested in pepsin under standard conditions of fixed concentrations at $\mathrm{pH} 1.2$ as a number of important food allergens were known to be stable in pepsin. The abundance of the protein and stability (of function) of the protein under heated conditions would also be considered as secondary additional characteristics of possible risk of allergy. This approach [37] was accepted by scientific panels organized by the FAO/WHO in 1996 and 2000 during joint Consultations on the safety assessment of genetically modified foods of plant origin. During an additional consultation of scientists, the FAO/WHO 2001 suggested a modified decision tree that changed criteria and broadened some of the previous approaches [57]. For sequence comparisons identity matches of $>35 \%$ over any segment of 80 or more amino acids or any $100 \%$ identity match of six or more contiguous amino acids significant would trigger specific IgE testing using sera from individuals allergic to the source of the matched allergen. In addition, targeted serum 
testing was suggested, where up to 50 individual donors allergic to broad taxonomic categories would be tested (e.g. those allergic to foods or pollen of various monocotyledons would be used if the gene was from any monocot). However, targeted screening would not be used if the gene was from a bacterium. Stability to digestion of the protein in pepsin would also be tested, but the using of two $\mathrm{pH}$ conditions (1.2 and 2.0) was recommended. The final recommendation was to attempt to sensitize two species of animals, or one species, but use two routes of exposure to evaluate the sensitizing potential of the purified GM protein. The Codex Alimentarius Commission reviewed the FAO/WHO 2001 guidelines among other recommendations and indicated that animal models have not been proven to be predictive, that the bioinformatics criteria of $>35 \%$ identity in 80 amino acid overlap by FASTA would be considered positive, that any short amino acid identity matches should be scientifically justified and that pepsin digestion could be performed at $\mathrm{pH} 1.2$ or 2.0 [58]. The Codex Alimentarius Commission did not recommend using targeted serum testing, but only specific testing to evaluate proteins expressed by genes taken from allergenic sources or proteins exceeding the bioinformatics criteria (above) [58,59]. Regulatory agencies in many countries including Canada, Australia and New Zealand, Japan, South Korea, Taiwan and the U.S. follow the Codex guidelines. The European Food Safety Authority (EFSA) [60] has developed slightly more explicit guidelines that are intended to be followed by members of the European Union [61]. The issue of heat stability has not been clearly demonstrated as predictive for food allergy as the relationship only appears to be useful for predicting risk if the unheated protein binds IgE or causes allergic reactions, but the recombinant protein expressing in a food source is always heated [62]. Then testing stability of IgE binding or elicitation of allergic reactions with heated protein should be used in risk assessment.

In China, the Ministry of Agricultural set the "Transgenic plant safety evaluation guidelines" to guide the application and safety evaluation of transgenic plant [63], and as reference of the safety assessment of transgenic animals. In this guideline, the data of bioinformatics, stimulation gastric stability was necessary in the allergenic evaluation.

In addition, an interpretation of many guidelines to require human serum tests using sera from individuals allergic to milk due to matches to bovine lactoferrin, or to egg due to matches to ovotransferrin as described in this research.

As discussed above, several methods containing bioinformatics analysis, stability to pepsin and serum tests were used to research the rhLF's allergenicity.

\section{Conclusion}

Based on the results of an evaluation process that follows Codex guidelines and considers history of safe use, there is no evidence to suggest that rhLF as expressed in transgenic cows, would pose a risk of allergy to consumers. So it may be added into food or formula powder to improve their nutrition condition.

\section{Acknowledgements}

We acknowledge our colleagues who contributed to this study. Besides, we thank the National Natural Sciences Foundation of China and China Agricultura University for the funding. This work was supported by a grant from the National Natural Sciences Foundation of China named "Research of animal models evaluation system on potential allergenicity." (No. 81072305) and the scientific research innovation special of China agricultural university postgraduate named "Research of human serology method used to evaluate the potential allergenicity of food." (NO. 2012YJ080).

\section{References}

1. Lönnerdal B, lyer S (1995) Lactoferrin: molecular structure and biological function. Annu Rev Nutr 15: 93-110.

2. Tenovuo J (2002) Antimicrobial agents in saliva--protection for the whole body J Dent Res 81: 807-809.

3. Tenovuo J, Lehtonen OP, Aaltonen AS, Vilja P, Tuohimaa P (1986) Antimicrobial factors in whole saliva of human infants. Infect Immun 51: 49-53.

4. Janssen PT, van Bijsterveld OP (1983) A simple test for lacrimal gland function a tear lactoferrin assay by radial immunodiffusion. Graefes Arch Clin Exp Ophthalmol 220: 171-174.

5. Metz-Boutigue MH, Jollès J, Mazurier J, Schoentgen F, Legrand D, et al. (1984 Human lactotransferrin: amino acid sequence and structural comparisons with other transferrins. Eur J Biochem 145: 659-676.

6. Håkansson A, Zhivotovsky B, Orrenius S, Sabharwal H, Svanborg C (1995) Apoptosis induced by a human milk protein. Proc Natl Acad Sci U S A 92: 8064-8068.

7. Levay PF, Viljoen M (1995) Lactoferrin: a general review. Haematologica 80 252-267.

8. Mazurier J, Spik G (1980) Comparative study of the iron-binding properties of human transferrins. I. Complete and sequential iron saturation and desaturation of the lactotransferrin. Biochim Biophys Acta 629: 399-408.

9. González-Chávez SA, Arévalo-Gallegos S, Rascón-Cruz Q (2009) Lactoferrin: structure, function and applications. Int J Antimicrob Agents 33: 301.

10. Jenssen H, Hancock RE (2009) Antimicrobial properties of lactoferrin Biochimie 91: 19-29.

11. Tomita M, Wakabayashi H, Shin K, Yamauchi K, Yaeshima T, et al. (2009) Twenty-five years of research on bovine lactoferrin applications. Biochimie 91 : 52-57.

12. Nibbering $\mathrm{PH}$, Ravensbergen $\mathrm{E}$, Welling MM, van Berkel LA, van Berkel $\mathrm{PH}$, et al. (2001) Human lactoferrin and peptides derived from its $\mathrm{N}$ terminus are highly effective against infections with antibiotic-resistant bacteria. Infect Immun 69: 1469-1476.

13. Soukka T, Tenovuo J, Lenander-Lumikari M (1992) Fungicidal effect of human lactoferrin against Candida albicans. FEMS Microbiol Lett 69: 223-228.

14. Zhang GH, Mann DM, Tsai CM (1999) Neutralization of endotoxin in vitro and in vivo by a human lactoferrin-derived peptide. Infect Immun 67: 1353-1358.

15. Harmsen MC, Swart PJ, de Béthune MP, Pauwels R, De Clercq E, et al. (1995) Antiviral effects of plasma and milk proteins: Lactoferrin shows potent activity against both human immunodeficiency virus and human cytomegalovirus replication in vitro. J Infect Dis 172: 380-388.

16. Tang XS, Tang ZR, Wang SP, Feng ZM, Zhou D, et al. (2012) Expression, purification, and antibacterial activity of bovine lactoferrampin-lactoferricin in Pichia pastoris. Appl Biochem Biotechnol 166: 640-651.

17. Nuijens JH, van Berkel PH, Schanbacher FL (1996) Structure and biological actions of lactoferrin. J Mammary Gland Biol Neoplasia 1: 285-295.

18. Håversen LA, Engberg I, Baltzer L, Dolphin G, Hanson LA, et al. (2000) Human lactoferrin and peptides derived from a surface-exposed helical region reduce experimental Escherichia coli urinary tract infection in mice. Infect Immun 68 : 5816-5823.

19. Håversen LA, Baltzer L, Dolphin G, Hanson LA, Mattsby-Baltzer I (2003) Antiinflammatory activities of human lactoferrin in acute dextran sulphate-induced colitis in mice. Scand J Immunol 57: 2-10.

20. Paesano R, Torcia F, Berlutti F, Pacifici E, Ebano V, et al. (2006) Ora administration of lactoferrin increases hemoglobin and total serum iron in pregnant women. Biochem Cell Biol 84: 377-380.

21. El-Loly M, Mahfouz MB (2011) Lactoferrin in relation to biological and applications: A review. Int J Dairy Sci 6: 79-111.

22. van Veen HA, Geerts ME, van Berkel PH, Nuijens JH (2002) Analytical cationexchange chromatography to assess the identity, purity, and $\mathrm{N}$-terminal integrity of human lactoferrin. Anal Biochem 309: 60-66.

23. Foley AA, Bates GW (1987) The purification of lactoferrin from human whey by batch extraction. Anal Biochem 162: 296-300. 
Citation: Zhou C, Sun N, Wang J, Lu J, Tian J, et al. (2013) Allergenicity Assessment of a Genetically Modified Protein-Recombinant Human Lactoferrin. J Aller Ther S3: 002. doi:10.4172/2155-6121.S3-002

24. Palman KP Elgar DF (2002) Detection and quantitation of lactoferrin in bovine whey samples by reversed-phase high-performance liquid chromatography on polystyrene-divinylbenzene. J Chromatogr A 947: 307-311.

25. Cao Y, Cao HY (2002) Research of human lactoferrin gene cloning and expression in cell. J Hered 24: 9-14.

26. Conesa C, Sánchez L, Rota C, Pérez MD, Calvo M, et al. (2008) Isolation of lactoferrin from milk of different species: calorimetric and antimicrobial studies. Comp Biochem Physiol B Biochem Mol Biol 150: 131-139.

27. Liang Q, Richardson T (1993) Expression and characterization of human lactoferrin in yeast saccharomyces cerevisiae. J Agr Food Chem 41: 1800 1807.

28. Chong DK, Langridge WH (2000) Expression of full-length bioactive antimicrobial human lactoferrin in potato plants. Transgenic Res 9: 71-78.

29. Ling XP, Pang GC (2003) The latest research advances of lactoferrin. Food Sci 24: 160-163.

30. Platenburg GJ, Kootwijk EP, Kooiman PM, Woloshuk SL, Nuijens JH, et al. (1994) Expression of human lactoferrin in milk of transgenic mice. Transgenic Res 3: 99-108.

31. Nuijens JH, van Berkel PH, Geerts ME, Hartevelt PP, de Boer HA, et al. (1997) Characterization of recombinant human lactoferrin secreted in milk of transgenic mice. J Biol Chem 272: 8802-8807.

32. Yang P, Wang J, Gong G, Sun X, Zhang R, et al. (2008) Cattle mammary bioreactor generated by a novel procedure of transgenic cloning for large-scale production of functional human lactoferrin. PLoS One 3: e3453.

33. Zhou C, Wang JW, Huang KL, He X, Chen XP, et al. (2011) A 90-day safety study in Sprague-Dawley rats fed milk powder containing recombinant human lactoferrin (rhLF) derived from transgenic cloned cattle. Drug Chem Toxicol 34: 359-368

34. Yu T, Guo C, Wang J, Hao P, Sui S, et al. (2011) Comprehensive characterization of the site-specific $\mathrm{N}$-glycosylation of wild-type and recombinant human lactoferrin expressed in the milk of transgenic cloned cattle. Glycobiology 21 : 206-224.

35. Altmann $F$ (2007) The role of protein glycosylation in allergy. Int Arch Allergy Immunol 142: 99-115.

36. Mullins RJ, James H, Platts-Mills TA, Commins S (2012) Relationship between red meat allergy and sensitization to gelatin and galactose- $\alpha-1,3$-galactose. J Allergy Clin Immunol 129: 1334-1342.

37. Metcalfe DD, Astwood JD, Townsend R, Sampson HA, Taylor SL, et al (1996) Assessment of the allergenic potential of foods derived from genetically engineered crop plants. Crit Rev Food Sci 36: S165-S186.

38. Herman RA, Song P, Thirumalaiswamysekhar A (2009) Value of eight-aminoacid matches in predicting the allergenicity status of proteins: an empirical bioinformatic investigation. Clin Mol Allergy 7: 9.

39. Goodman RE, Tetteh AO (2011) Suggested improvements for the allergenicity assessment of genetically modified plants used in foods. Curr Allergy Asthma Rep 11: 317-324.

40. Goodman RE, Vieths S, Sampson HA, Hill D, Ebisawa M, et al. (2008) Allergenicity assessment of genetically modified crops--what makes sense? Nat Biotechnol 26: 73-81.

41. Goodman RE, Silvanovich A, Hileman RE, Bannon GA, Rice EA, et al. (2002) Bioinformatic Methods for Identifying Known or Potential Allergens in the Safety Assessment of Genetically Modified Crops. Comments Toxico 8: 251-269.

42. Goodman RE (2006) Practical and predictive bioinformatics methods for the identification of potentially cross-reactive protein matches. Mol Nutr Food Res 50: $655-660$

43. Hileman RE, Silvanovich A, Goodman RE, Rice EA, Holleschak G, et al. (2002) Bioinformatic Methods for Allergenicity Assessment Using a Comprehensive Allergen Database. Int Arch Allergy Immunol 128: 280-291.

44. Chinese standard NO.869-2 Announcement of Ministry of agriculture (2007) Food safety detection of genetically modified organisms and derived products:
Method of target protein digestive stability in simulative gastric and intestinal fluid.

45. Adel-Patient K, Bernard H, Ah-Leung S, Créminon C, Wal JM (2005) Peanutand cow's milk-specific lgE, Th2 cells and local anaphylactic reaction are induced in Balb/c mice orally sensitized with cholera toxin. Allergy 60: 658-664.

46. Tong P, Gao J, Chen H, Li X, Zhang Y, et al. (2012) Effect of heat treatment on the potential allergenicity and conformational structure of egg allergen ovotransferrin. Food Chem 131: 603-610.

47. Aalberse RC (2000) Structural biology of allergens. J Allergy Clin Immunol 106 : 228-238.

48. Martos G, López-Fandiño R, Molina E (2013) Immunoreactivity of hen egg allergens: influence on in vitro gastrointestinal digestion of the presence of other egg white proteins and of egg yolk. Food Chem 136: 775-781.

49. Chen L, Lucas JS, Hourihane JO, Lindemann J, Taylor SL, et al. (2006) Evaluation of IgE binding to proteins of hardy (Actinidia arguta), gold (Actinidia chinensis) and green (Actinidia deliciosa) kiwifruits and processed hardy kiwifruit concentrate, using sera of individuals with food allergies to green kiwifruit. Food Chem Toxicol 44: 1100-1107.

50. Peeters KA, Nordlee JA, Penninks AH, Chen L, Goodman RE, et al. (2007) Lupine allergy: not simply cross-reactivity with peanut or soy. J Allergy Clin Immunol 120: 647-653.

51. Hoff M, Son DY, Gubesch M, Ahn K, Lee SI, et al. (2007) Serum testing of genetically modified soybeans with special emphasis on potential allergenicity of the heterologous protein CP4 EPSPS. Mol Nutr Food Res 51: 946-955.

52. Steinhoff M, Fischer M, Paschke-Kratzin A (2011) Comparison of extraction conditions for milk and hen's egg allergens. Food Addit Contam Part A Chem Anal Control Expo Risk Assess 28: 373-383.

53. Shalev I, Schmelzle M, Robson SC, Levy G (2011) Making sense of regulatory T cell suppressive function. Semin Immunol 23: 282-292.

54. Mari A (2002) IgE to cross-reactive carbohydrate determinants: analysis of the distribution and appraisal of the in vivo and in vitro reactivity. Int Arch Allergy Immunol 129: 286-295.

55. Jin C, Hantusch B, Hemmer W, Stadlmann J, Altmann F (2008) Affinity of IgE and IgG against cross-reactive carbohydrate determinants on plant and insect glycoproteins. J Allergy Clin Immunol 121: 185-190.

56. Kaulfürst-Soboll H, Mertens M, Brehler R, von Schaewen A (2011) Reduction of cross-reactive carbohydrate determinants in plant foodstuff: elucidation of clinical relevance and implications for allergy diagnosis. PLoS One 6: e17800.

57. FAO/WHO (2001) Evaluation of allergenicity of genetically modified foods Report of a joint FAO/WHO expert consultation on allergenicity of foods derived from biotechnology. Rome, Italy.

58. Codex (Codex Alimentarius Commission) (2006) Reports of the sixth session of the Codex ad hoc intergovernmental task on foods derived from biotechnology. CL 2006/54 - FBT

59. Codex (Codex Alimentarius Commission) (2008) Guideline for the conduct of food safety assessment of foods derived from recombinant-DNA animals. CAC/ GL 68-2008. In: Foods derived from modern biotechnology, 2nd ed. Rome Italy: World Health Organization, Food and Agriculture Organization of the United Nations. Rome, Italy.

60. (2006) Guidance Document of the Scientific Panel on Genetically Modified Organisms for the Risk Assessment of Genetically Modified Plants and Derived Food and Feed. The EFSA Journal 99: 1-100.

61. EFSA Panel on Genetically Modified Organisms (GMO) (2011) Scientific Opinion on Guidance for risk assessment of food and feed from genetically modified plants. The EFSA Journal 9: 2150.

62. Goodman RE, Hefle SL (2005) Gaining perspective on the allergenicity assessment of genetically modified food crops. Expert Rev Clin Immunol 1 : 561-578.

63. The Ministry of Agriculture of the People's Republic of China (2006) Guideline for safety assessment of food from genetically modified plant and derived products. 